University of Nebraska - Lincoln

DigitalCommons@University of Nebraska - Lincoln

USDA Wildlife Services - Staff Publications

U.S. Department of Agriculture: Animal and Plant Health Inspection Service

2019

The Role of Scavenging in Disease Dynamics

Joaquín Vicente

Instituto de Investigación en Recursos Cinegéticos, Joaquin.Vicente@uclm.es

Kurt C. Vercauteren

USDA/APHIS/Wildlife Services, kurt.c.vercauteren@usda.gov

Follow this and additional works at: https://digitalcommons.unl.edu/icwdm_usdanwrc

Part of the Natural Resources and Conservation Commons, Natural Resources Management and Policy Commons, Other Environmental Sciences Commons, Other Veterinary Medicine Commons, Population Biology Commons, Terrestrial and Aquatic Ecology Commons, Veterinary Infectious Diseases Commons, Veterinary Microbiology and Immunobiology Commons, Veterinary Preventive Medicine, Epidemiology, and Public Health Commons, and the Zoology Commons

Vicente, Joaquín and Vercauteren, Kurt C., "The Role of Scavenging in Disease Dynamics" (2019). USDA Wildlife Services - Staff Publications. 2287.

https://digitalcommons.unl.edu/icwdm_usdanwrc/2287

This Article is brought to you for free and open access by the U.S. Department of Agriculture: Animal and Plant Health Inspection Service at DigitalCommons@University of Nebraska - Lincoln. It has been accepted for inclusion in USDA Wildlife Services - Staff Publications by an authorized administrator of DigitalCommons@University of Nebraska - Lincoln. 


\title{
The Role of Scavenging in Disease Dynamics
}

\author{
Joaquín Vicente and Kurt VerCauteren
}

\section{Contents}

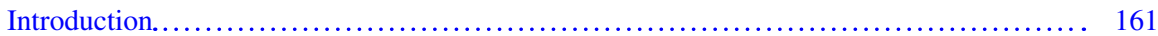

The Use of Animal Remains and the Exposure of Scavengers to Disease................. 163

The Relevance of Scavenging for Pathogens to Spread and Persist...................... 166

Human Related Factors Resulting in Increased Risk for Disease Transmission Through

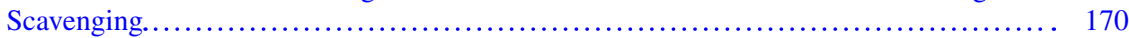

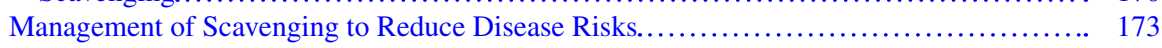

Restoration of Large Predators.............................................. 174

Elimination of Hunting of Scavengers......................................... 174

Destruction of Big Game and Domestic Animal Carcasses.......................... 174

Restoration of the Effects of Overabundance.................................... 175

Excluding Mammalian and Avian Scavengers from Natural Carrions................... 176

Excluding Mammalian and Avian Scavengers from Vulture Restaurants............... 176

Conclusions and Future Perspectives............................................. 178

References.................................................................. 178

\section{Introduction}

Scavenging is a widespread strategy among vertebrates with an important contribution to food webs and ecosystem function (see chapter "Carrion Decomposition"). Among the important ecosystem functions and services supported by scavengers, the control of disease spreading from decomposing carcasses is frequently highlighted as a major argument for scavenger conservation. Particularly, obligate scavengers (vultures) seem to reduce the risk of disease in the community, including

\footnotetext{
J. Vicente $(\bowtie)$

SaBio - Instituto de Investigación en Recursos Cinegéticos, IREC (UCLM-CSIC),

Ciudad Real, Spain

e-mail: Joaquin.Vicente@uclm.es

K. VerCauteren

National Wildlife Research Center, USDA/APHIS/Wildlife Services, Fort Collins, CO, USA

e-mail: kurt.c.vercauteren@aphis.usda.gov
} 
humans (e. g. Markandya et al. 2008). Scavenging can potentially reduce the spread of disease among wildlife because many pathogenic organisms in carcasses cannot survive passage through the highly acidic digestive system of vultures (Houston and Cooper 1975). A reduction in the numbers of vultures and/or the effects of anthropogenic factors can lead to increasing consumption by facultative scavengers, i.e. those apecies not relying on scavenging to survive but utilizing carrion when it is available (Markandya et al. 2008; Ogada et al. 2012; Mateo-Tomás et al. 2015; Inger et al. 2016). The role these changes in scavenging dynamics have on ecological and sanitary issues is a matter of debate. Moreover, important knowledge gaps exist relative to the role of different scavenging species in disease dynamics at carcasses, especially under the current scenario of increasing anthropization of natural ecosystems.

In this chapter, we address aspects of the transmission of diseases by or facilitated by scavenging, and under which conditions, reviewing and synthesizing past research. We define future research needs in this field aimed to address knowledge gaps on the issue. We must keep in mind that in many ecosystems, diseases provide important mechanisms to regulate animal populations, and that death from disease produces from occasional short-term to large long-term pulses of carrion into ecosystems (see chapter "Carrion Availability in Space and Time" and this chapter). Scavenged material can potentially favor transmission and spread of infectious diseases or contaminants to wild animals, the environment and the human-related compartment; or contrary, scavenging can limit pathogen spread. Finally, we address human-related factors that influence pathogen spread by scavenging and its management.

It is still necessary to improve the basic knowledge of the epidemiology of wildlife diseases in order to understand the role of scavenging in disease dynamics. Studying wildlife disease is challenging, particularly the study of aspects regarding pathogen transmission and the mechanisms of perpetuation in the host community and the environment. There are many concurrent factors of very different nature, especially when diseases are shared among different hosts, some of which can act as facilitators or vectors of pathogen spread. Also, the role varying environments play poses unique challenges. For instance, ferrets (Mustela furo) and wild boar (Sus scrofa) are considered to act as a host complex (via reciprocal scavenging) relative to the transmission of tuberculosis (TB) in New Zealand, and the combined effects of these species on pathogen transmission are proposed to be density dependent (Barron et al. 2015). We must also consider host-pathogen adaptations and life history strategies. Different mechanisms, modes of transmission and strategies for pathogens to persist are possible, and they can operate differently according to local circumstances. A given pathogen, host and scavenging community assemblage, under different conditions, may present variable contributions to pathogen spread by scavenging, from promotion to prevention. Most pathogens that are transmitted through predation or scavenging do not have to leave the body of the host for transmission to occur, but are passively ingested, such as mycobacteria species causing tuberculosis. Some other pathogens may leave the carcass and persist in the environment, or are spread by vectors, which may be facilitated by previous carcass 
opening by scavengers; which includes pathogens highly resistant in the environment, such as anthrax - an acute fatal multi-species disease caused by the bacterium Bacillus anthracis. In the last instance, understanding all the epidemiological and ecological processes is key to managing disease and scavenging in the wild for a given purpose; for instance, reducing pathogen spread in human intervened systems where the number of vultures has been reduced, and preventing endangered facultative scavengers from becoming infected via scavenging.

We identify some important aspects that are central in current and future research regarding the role of scavenging in disease dynamics. (1) The use of animal remains by scavengers and their exposure to disease. Little is still known about this issue, in spite of it being a first step required to understand the exposure of scavenger communities to disease, and to subsequently guide specific research on the potential role of scavenging in pathogen spread. This aspect is also key to identify different epidemiological contexts and patterns of consumption. (2) The relevance of scavenging for pathogens to spread and persist. Scavenging is likely limiting pathogen spread in many systems. Scavengers have also been implicated as potential vectors for a number of diseases, and facilitators of disease spread once they open the carcass, contaminating the vicinity and enabling the action of vectors. (3) Human-related factors resulting in increased risk of pathogen transmission through scavenging. Disease emergence and re-emergence in the wild, impacting natural populations, tends to occur more in ecosystems altered by human activities, affecting hostpathogen-environment relationships. This phenomena may lead to increased amounts of contaminated material, leaving extremely resistant agents in the environment and may also affect scavenger community-carrion dynamics and contact rates among susceptible scavenger hosts and infected material. (4) Management of scavenging to reduce disease risks. Preventing the entrance and/or controlling levels of disease in environments is the first approach. Once disease is present, re-directing scavenging activity and restoring scavenger communities might provide useful strategies to reduce disease risks.

\section{The Use of Animal Remains and the Exposure of Scavengers to Disease}

Exposure to disease mediated by scavenging results as a consequence of both a given pattern of carrion use by scavengers and the presence of a disease in the system. While consumption poses the highest risk, the use of carrion in relation to pathogen exposure does not necessarily involve scavenging, but other risky behaviors such as exploring the environment (direct exposure to pathogens in the environment or vectors) or consuming invertebrates. For instance, wild boar explore in the soil next to and under the carcasses of conspecifics, sniffing and poking the carcass (Probst et al. 2016). Regarding carrion use by scavengers, several studies have been conducted using a variety of carrion (e.g. from entire carcasses to gut piles) to monitor scavenger activity (e. g. DeVault et al. 2003; Wilmers et al. 2003a, b, Roen and 
Yahner 2005; Selva et al. 2005; Mateo-Tomás et al. 2017; Carrasco-Garcia et al. 2018). These studies determine rates of activity and consumption by scavengers, and the decomposition of animal remains in specific situations. Every study addresses a particular situation, representing different scavenger assemblages, localizations and types of carrion material (carcasses, gut piles, abortions, etc.). A review by Mateo-Tomás et al. (2015) concerning ungulate carrion availability on a global scale (and references therein) found that although scavenger communities consuming remains of hunter-killed animals vary among regions, a common pattern emerges in which birds and mammals dominate consumption. They found scavenging birds to consume twice as much as mammals, but that more mammal than bird species took part in scavenging (Mateo-Tomás et al. 2015). Facultative scavengers (i.e. mainly generalists and apex predators) dominate consumption everywhere, especially where the presence of obligate scavengers (vultures) and apex predators (e.g. wolves Canis lupus, hyenas, and eagles) is low. Suids (i.e. wild boar) are also frequent scavengers where present. Often species of other taxonomic groups, such as reptiles and invertebrates, function as scavengers (see chapters "Invertebrate Scavenging Communities" and "Vertebrate Scavenging Communities"). For example, blowflies have been suspected to play an important role in anthrax transmission (Bellan et al. 2013). Determining the relative contribution of specialized as compared to facultative scavengers would provide relevant insights into their risk of exposure to disease and the relevance of scavenging in disease dynamics. Vultures consume carcasses quickly, and their absence is usually associated with significantly slower decomposition rates (Mateo-Tomás et al. 2017), leading to higher abundances of facultative scavengers that spend a longer time in close to carcasses (Ogada et al. 2012). These studies also differentiate between which species or individuals are true scavengers and which act merely as visitors, or exceptionally, as scavengers due to very particular rare behavior displayed by particular individuals. For instance, it has even been reported that some deer species may consume animal tissues, including flesh, digestive content and bone of dead animals (e.g., Cook et al. 2004; Vicente et al. 2011).

Researchers must also pay attention to the specific tissues that scavengers consume, relating this potentially infection risk. For instance, large carrion birds do not usually consume bovine central nervous tissue, but do consume their intestines and, occasionally, ovine central nervous system tissue (or at least the spinal medulla), which may determine their exposition to prions (European Commission 2002). Also, selective particularities for different scavengers can be determined. For instance, there is anecdotal evidence that feral pigs may avoid feeding on ferret carcasses, whereas they readily consume brushtail possum (Trichosurus vulpecula) carcasses in New Zealand (Byrom 2004). Determining the temporal patterns of scavengers consuming carcasses, as well as the degree of persistence of carcasses and/or remains is very informative because it may facilitate the understanding of disease dynamics for animals and vectors that visit carcasses and/or consume carrion. The persistence of carcasses and/or remains also determine the relative contribution of microbial and invertebrates in the removal of dead material from the environment. Studying the biotic and abiotic factors that affect rates of carcass con- 
sumption and decomposition in the environment is essential to explain variations in the relative contribution of scavengers under different scenarios (Jennelle et al. 2009; Vicente et al. 2011; Turner et al. 2017) and subsequent exposure to disease. For instance, the role of facultative scavengers, wild boar and red fox (Vulpes vulpes), greatly varies between habitats (open vs vegetation covered) and scavenging community (presence of vultures vs absence; Vicente et al. 2011).

The typical procedure to perform these studies consists in randomly placing carcasses and/or remains throughout the landscape, or performing the study in situ where remains are produced (naturally through, for example, predation, disease, accident, or hunting). The activity of scavengers in recent research is usually monitored by using remotely activated cameras, and then it is quantified (e.g. Mateo-Tomás et al. 2015, 2017). The use of infrared lights minimizes disturbance to scavengers, particularly mammals, which can be affected by direct observations. It is recommended to check in situ the status of the carrion to describe the amount of material that is left, the parts that have been removed, and any activity that is difficult to record with cameras (e.g. invertebrate activity). This has to be carried out such that normal activity of scavengers is not disrupted. The use of cameras can reveal the representative scavenger communities (and visitors) of carrion (carcasses or gut piles). Nonetheless, photographic evidence that some scavengers consume some specific $c$ arcass $m$ aterials is difficult to as sess since different species may overlap in a period of time, and pictures or videos do not always clarify this. At this stage, scavenging can only be related with increased exposure to infectious materials, but this does not necessarily involve transmission of pathogens.

As aforementioned, it is necessary to combine descriptive data on scavenging activity with the collection, analysis and interpretation of wildlife and/or livestock disease data. Most of the available information of disease in many animal communities is based on punctual "surveys" of disease, which are not specifically designed to analyze health risks. Therefore, this information is not sufficient. By contrast, disease "surveillance" and "monitoring" programs usually refer to ongoing processes and provide opportunities to analyze risk related to scavenging activity. These programs first provide information on the causes of wildlife loss other than predation, such as starvation, disease, trauma (e.g. collisions with vehicles, fences), injuries sustained while fighting, other wounds, and pesticide exposure, among others. Surveillance is specifically designed to analyze and manage any associated health risks (Artois et al. 2009), and data are used to identify the areas to be targeted for control, and to anticipate management interventions to reduce disease risks. The actions taken can be passive (or reactive, obtaining information on the disease agent in sick or dead animals) or active (actively searching for the disease in animals through sampling). Further, it is important to detect spatial and temporal trends as well as the presence/absence of the disease. Monitoring addresses the estimation of epidemiological parameters related to a defined disease, such as prevalence (infected relative to population), incidence (new infected relative to susceptible population) and the basic reproductive number $\mathrm{R}_{0}$ (the number of secondary cases which a first infection case would produce in a population free of pathogens; it explains whether 
a disease will die out or whether it may become epidemic if $R_{0}>1$ ). Monitoring is always based on an active approach (searching for diseased animals, sampling and testing). Data and samples gathered can then be used for detecting emerging diseases, spatiotemporal variation in patterns of disease spread and persistence, and finally, for assessing what the relationships with variations in scavenging activity maybe (i.e. the factors determining risks of pathogen transmission by scavenging). A nice example is brucellosis (Brucella abortus) in the Greater Yellowstone Area in western Wyoming, USA, where it is endemic in elk (Cervus elaphus nelsoni) using winter feed grounds. This is so, presumably, because of increased animal density, duration of attendance, and subsequent contact with aborted fetuses. Maichak et al. (2009), rather than only measuring levels of disease in the population, or just describing scavenging on aborted fetuses, addressed both aspects complementary.

Sentinel surveillance can be used for the detection of pathogens, especially those that are newly because sentinel species or individuals are often more at risk of infection than other animals (e.g. reservoir of disease or obligate scavengers). A sentinel wildlife species acquires infection primarily or exclusively from a sympatric wildlife maintenance host, or from the environment where the infected host was located (Anderson et al. 2015). A sentinel species normally is not itself a major part of the pathogen but is predominantly a spillover host, it is easily infected and remains alive in an infected state for months or years, and thus available for detection. Sentinel species may also have much larger ranging areas than maintenance hosts. The use of wildlife sentinels may be a particularly valuable approach to surveillance for emerging zoonotic infections, many of which have their origins in wild hosts. Certain taxa may be relatively more efficient at concentrating some pathogens, for instance predators at the top of food chains or scavengers that may be exposed to infectious carcasses (Smith 1994; Leighton et al. 1995). For example, coyotes (Canis latrans), wild boar and ferrets carrying Mycobacterium bovis that causes tuberculosis in wildlife may be used as sentinels during disease surveillance (VerCauteren et al. 2008; Byrom et al. 2015).

\section{The Relevance of Scavenging for Pathogens to Spread and Persist}

Although for many pathogens horizontal transmission via scavenging (or facilitated by) of contaminated material is possible, the consequences for disease dynamics are unknown in most cases. Studying wildlife diseases is challenging, and it is especially difficult to disentangle the relative contribution of scavenging-related factors to the spread and maintenance of diseases in ecosystems. Experiments may help to assess the possibility of cross-species pathogen transmission by scavenging, and empirical observations in the field can support those assessments on the potential risk for transmission. Nonetheless, the relevance of scavenging for pathogens to persist must be specifically assessed for each system and epidemiological context. 
Scavenging is probably limiting disease spread in most cases, even when scavengers become infected. The concept of disease reservoir is relevant to understand disease maintenance and management in relation to scavenging. Briefly, an infected animal population can be classed as either a maintenance or spillover host, depending on the dynamics of the infection. In a maintenance (true reservoir) host, infection can persist by intraspecies transmission alone, and may also be the source of infection for other species. In a spillover host, infection will not persist indefinitely unless there is re-infection from another species or the environment. For instance, surveys of carnivores and omnivores from Michigan have confirmed M. bovis (one of the causative agents of animal TB) infection in coyotes, bobcats (Felis rufus), red foxes, black bears (Ursus americanus), opossums (Didelphis virginiana), raccoon (Procyon lotor) and domestic cats (Felis silvestris catus; Bruning-Fann et al. 2001). Molecular techniques have evidenced that deer and other wildlife are infected with a common strain of $M$. bovis, and the species above-mentioned likely become infected through scavenging of deer or domestic cow carcasses. However, infection with limited lesion development in the scavenger species suggests they are spillover hosts and not important in the maintenance of the epizootic in deer or transmission to other susceptible hosts. A similar situation regards the red fox in Europe (Delahay et al. 2006; Millan et al. 2008). TB cases in red fox only suggest opportunities for infection with the MTC when it is present in the natural environment, but this species is considered a spillover host. TB may affect species of interest for conservation, such as the endangered Iberian lynx (Lynx pardinus) that inhabits the Iberian Peninsula of Spain, although its epidemiological role for TB maintenance in the host community is insignificant (Briones et al. 2000; Pérez et al. 2001). The consumption of infected ungulate carrion in the Iberian Peninsula may contribute to the spread and persistence of TB in wildlife with regard to omnivorous species like wild boar, rather than avian scavengers (e.g. Gyps vultures; see below) that effectively remove infectious sources (Vicente et al. 2011). Regarding Brucella in elk, Maichak et al. (2009) monitored pseudo-aborted elk fetuses, placentas, and fluids in winter. Since many scavengers in the study area were migratory, canids and sedentary facultative scavenger birds accounted for most of the scavenging. Among mammals, coyotes, wolves and, presumably, red fox can be infected with brucellosis likely from ingestion of contaminated tissues or fluids, although they are spillover hosts. Interestingly, they found that scavengers reduced the proportion of elk exposed to aborted material, illustrating that scavengers native to the area likely function as biological control agents of disease. Cannibalism after Aujeszky's disease outbreaks (a viral disease of swine and wild boar that can affect most mammals except humans and primates) in wild boar has been related to pathogen transmission (Gortazar et al. 2002), although the relevance of scavenging is punctual and short-term. Anecdotally, scavenging Aujeszky's virus infected material is a risk for carnivores, such as the Florida panther (Felis concolor corii), the European brown bear (Ursus arctos; Glass et al. 1994; Zanin et al. 1997) and the endangered Iberian lynx (Masot et al. 2016), although without relevance for disease maintenance. 
The number of contacts among conspecific mammals at a $\mathrm{c}$ arcass $\mathrm{c}$ an a lso potentially facilitate pathogen transmission. Ogada et al. (2012) determined a nearly threefold increase in the mean number of contacts among mammalian scavengers at carcasses without vultures, highlighting the role of vultures in carcass decomposition and level of contact among mammalian scavengers. Nonetheless, while aggregation and intraspecific contact at carcasses is frequently reported as a likely source of horizontal pathogen transmission for several scavengers (e.g. carnivores; Markandya et al. 2008; Ogada et al. 2012; Newsome et al. 2014), the role of most scavengers in the transmission dynamics of pathogens from carcasses remains widely unknown and even misunderstood. A special example is the potential risk of anthrax spread associated with scavenging activity (Bellan et al. 2013). Anthrax epidemiology is driven by environmental conditions and its preferred hosts vary amongst habitats and ecosystems. After an animal dies from anthrax, when the carcass is opened by scavengers sporulation of bacteria takes place. Spores can be disseminated indirectly by: blowflies, which contaminate browse in the vicinity; vultures and mammalian scavengers, which contaminate water supplies (by bathing and defecating in it or the soil nearby); water run-off contaminating the grazing in the vicinity; and directly by scavengers eating from the carcass or chewing on old bones (herbivores with osteophagia; Hutson et al. 2013). Though scavenger species are relatively resistant to this pathogen, the spores are very resistant in the environment. Sporulation of bacteria occurs primarily after scavengers have opened an infected fresh carcass and the tissues have been exposed to the air, and the number of spores produced is therefore dependent on an early opening of an anthrax-infected carcass. Vultures may disseminate the infection, yet they may curtail its spread by locating carcasses shortly after death and minimizing contamination by rapidly consuming smaller and thin-skinned carcasses before most of the vegetative forms have had time to sporulate (Bellan et al. 2013).

Experimental research has determined susceptibility of scavenger species to particular infections and the likelihood of pathogen passage through the gastrointestinal tract. The digestive system of obligate scavengers such as vultures present conditions of extreme acidity, around $\mathrm{pH} \mathrm{1-1.2} \mathrm{in} \mathrm{the} \mathrm{stomach} \mathrm{(Houston} \mathrm{and}$ Cooper 1975; Farner 1967). These conditions in the digestive tract of carrion birds probably provide helpful factors both to digest carrion and as a form of protection against biological agents. Nonetheless, their effect on prions has not been fully confirmed, s ince prion p roteins a re m ore s ensitive to a lkalinity than to a cidity. Transmissible spongiform encephalopathies (TSEs) are a group of diseases caused by prions that affect the brain and nervous system of humans and animals. These include bovine spongiform encephalopathy (BSE), Scrapie and chronic wasting disease (CWD). CWD is a geographically expanding prion TSE of North American cervids (Nichols et al. 2015) first described in the United States in 1967. Prions can remain viable in the environment for many years (Seidel et al. 2007). During decomposition, ungulate carcasses release nutrients into surrounding soils, stimulate subsequent plant biomass production that attracts herbivores, and serve as a potential source of infectious material (Towne 2000; Miller et al. 2004). Avian and 
mammalian scavengers that consume infected materials could spread prions through deposition of feces in the environment (Houston and Cooper 1975) or by transport of infectious carrion during food-catching or young-provisioning. For instance, American crows (Corvus brachyrhynchos) have the potential to translocate infectious CWD prions in their feces to disease-free areas, which suggests that avian scavengers may play a role in the transmission and translocation of prion diseases (VerCauteren et al. 2012). It has been reported that the ability of CWDinfected brain material to pass through the gastrointestinal tract of coyotes following oral ingestion, and be infectious, demonstrating that mammalian scavengers could contribute to the translocation and contamination of CWD in the environment (Nichols et al. 2015). Currently, there is very low incidence of BSE in Europe; for instance, only 5 cases were diagnosed in cattle during 2016 (out of 1,352,585 animals tested) in the EU (8EFSA 2017). Only one of these cases was classified as classical BSE. However, five cases of CWD were reported in Norway: three in wild reindeer (Rangifer tarandus) and two in moose (Alces alces). This situation, in addition to the fact that no role for BSE spread by obligate scavengers has been demonstrated in Europe, led to modifying EU legislation that allowed for the conservation of scavenging birds to allow them to assist with carcass removal (Margalida et al. 2012, Margalida and Colomer 2012).

The modelling of disease dynamics can be useful to study the contribution of scavenging to disease spread and/or persistence, although it is difficult to parameterize scavenging rates between hosts. It has rarely been estimated between-host transmission parameter from scavenging estimates for a particular disease, particularly in the case of TB (Barron et al. 2015). The rates reported were likely not very accurate (as it assumed all scavenging of an infected carcass resulted in disease transmission and assumed that carcasses are contacted or scavenged within the period that $M$. bovis bacteria remain viable). Nonetheless, in multi-host systems, these rates provide comparable data among species that can be useful to model disease and the contribution of scavenging. Barron et al. (2015) concluded that TB could persist in the wild boar/ferret complex in the absence of possum hosts since scavenging would provide a source of spillback infection for possums once their numbers recovered even many years after control. Nonetheless, transmission rate estimation is complex and model outputs are sensitive to variations of several parameters, generating uncertainties. Estimation of these transmission parameters is required to enable managers to assess if multi-host disease dynamics are important for their disease control programs.

Figure 1 illustrates the risk of infectious disease spread, or contrary, disease control, through scavenging on mammals. This is a simplified scenario and the diversity of pathogens, epidemiological contexts, routes of transmission and scavenging assemblages make every case singular. Since the range of hosts a pathogen infects (host specificity) depends on shared phylogenetic history (Clark and Clegg 2017), pathogen circulation through scavenging is more probable from mammal to mammal. For instance, when ungulate carcasses are available, facultative ungulate scavengers, such as wild boar, are more susceptible to pathogens present in the scavenged material (especially when cannibalism occurs) than are birds. 


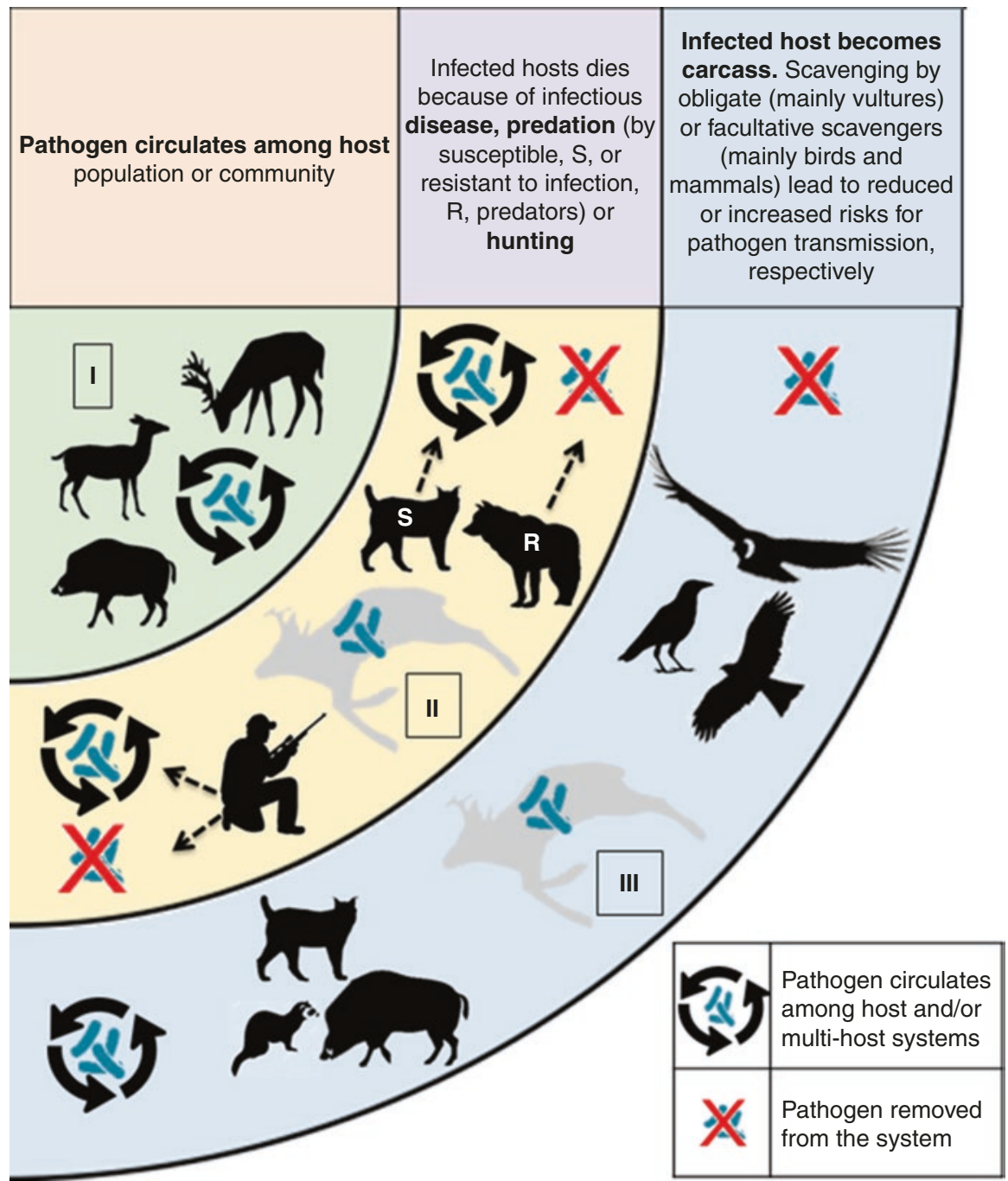

Fig. 1 Simplified scenario on the risk of infectious disease spread, or contrary, disease spread prevention through scavenging on mammal carrion. Credit: the chapter authors

\section{Human Related Factors Resulting in Increased Risk for Disease Transmission Through Scavenging}

Human activities may lead to increasing amounts of contaminated carrion, leaving extremely resistant agents in the environment. This, together with human impacts on scavenger communities (e.g. threats on top predators like vultures or other scavengers with key roles in ecosystems; Mateo-Tomás et al. 2017; or big game 
overabundance consequences, and particularly, facultative scavengers, such as wild boar; Gortazar et al. 2006) may increase contact rates among susceptible scavenger hosts and infected material. These situations are likely particular cases of disease emergence and re-emergence tending to occur more in ecosystems altered by humans (e.g. Daszak et al. 2000). Alterations to host-parasite relationships result in changes in host survival and contact rates among susceptible and infected individuals (Pedersen et al. 2007). This issue could acquire special relevance in the light of global environmental changes that can alter the patterns and prevalence of disease (Wilson and Wolkovich 2011).

Species considered big game vary with geographical areas and generally includes medium to large size ungulates and predators. Such a diverse group of species plays essential roles in the ecological dynamics of natural or semi-natural systems (e.g. Apollonio et al. 2010). Harvests that collect only part of animals, such as big game hunting, leave the remaining biomass for scavengers (Mateo-Tomás et al. 2015). For instance, there are some 20 species of big game within Europe (Cervidae, Bovidae, Ovidae and Suidae) adding up to 15 million animals and representing a standing biomass of more than 0.75 billion $\mathrm{kg}$ (Apollonio et al. 2010). In practice, there may be slight differences in the final presentation of the dressed carcass due to local cultural practices, type of trophy and final carcass use. In such ways, human activities could directly increase carrion supply and hence the prevalence of scavenging. Big game management by humans may contribute to the establishment and subsequent maintenance of pathogens that affects scavengers (especially facultative), the rest of the animal community and the environment (Vicente et al. 2011). High rates of pathogen circulation driven by human management are often associated to overabundance of big game; and in these cases, some infected species often play a role as facultative scavenger (e. g. wild boar, Gortazar et al. 2006). In addition, the way big game waste is disposed of may allow for facultative diseasesusceptible scavengers to access infected material (Moreno-Opo et al. 2012; Cano-Terriza et al. 2018). For instance, in Europe, as in many other parts of the world, the changes occurring across the last 40 years have had a pronounced effect on the environment, creating a dynamic situation where pathogens or new hosts emerge o re-emerge. In particular, there have been important changes in big game population densities and/or host behavior (management favoring aggregation, Acevedo et al. 2007), which affect disease prevalence and, in some cases, may allow disease agents to boost their virulence and widen their host range (Ferroglio et al. 2011). In south and central Spain, big game is frequently managed in order to promote high densities on hunting estates, and also reach considerably high densities in protected areas (Acevedo et al. 2007). This risk is increased by the sanitary consequences of ungulate overabundance caused by intensive management, which favor the transmission of disease and its persistence in ungulates (e.g. by increasing aggregation, and therefore contacts, at feeding and water points, Gortazar et al. 2006; Acevedo et al. 2007). These systems often generate a huge amount of hunting remains highly aggregated in both space (the remains are often disposed of at the same dumps) and time (e.g. big game hunting occurs mostly in autumn and winter; Vicente et al. 2011). TB averages 45\% (locally, even higher, Gortazar et al. 2008) of 
prevalence based on macroscopic lesions in wild boar in south and central Spain (Martín-Hernando et al. 2007). The importance of the intraspecific transmission of TB may be especially relevant in certain areas because of the absence of vultures, and the fact that wild boar, the main carrier of the disease in Spain (Naranjo et al. 2008), is the principal consumer of ungulate carrion provided by hunting. The consumption of infected ungulate carrion and waste may subsequently contribute to the spread and persistence of TB in wildlife with regard to carnivorous and omnivorous species rather than avian scavengers, which effectively remove infectious sources (see above and Fig. 1 in chapter "Ecological Functions of Vertebrate Scavenging"). In this context, controversy has arisen concerning vulture conservation, since European sanitary policies (e.g. Decision 2000/418/EC) encouraged the destruction of domestic animal carcasses (although EU Regulation 142/2011 allows now some exceptions; see this chapter), rather than being left in the open (Donázar et al. 2009a, b), and this scenario could also apply to the management of big game carcasses and hunting remains (Margalida and Moleón 2016).

Also, collateral effects of human activities may occur on diseases that are not (mainly) transmitted by scavenging. These cases usually relate to human intervention altering the host community, for instance, reducing the number of specialist scavengers, or favoring the abundance of generalist scavengers that participate in the spread and/or perpetuation of diseases, not necessarily transmitted by scavenging. Small predators, which are well-known disease reservoirs (e.g. rats Rattus spp., feral dogs Canis familiaris) appear to increase in abundance when vultures are absent in India (Pain et al. 2003). Diclofenac (a non-steroidal anti-inflammatory drug) residues in the tissues of treated dead cattle have been found to be highly toxic to vultures, resulting in up to $99 \%$ mortality in some species in India (also in Pakistan and Nepal, Markandya et al. 2008). The decline in vultures has favored an increase in packs of rabies-carrying feral dogs scavenging cattle remains. As a consequence, the number of cases of rabies in people due to dog bites has since increased (Oaks et al. 2004; Sharp 2006; Markandya et al. 2008). Similarly, spotted hyenas (Crocuta crocuta) and jackals (Canis aureus, C. mesomelas and $C$. adustus) host a number of pathogens that infect a wide range of other wild and domestic species (Alexander et al. 1994; Harrison et al. 2004). Two major diseases that affect African carnivores, rabies and canine distemper, spread through direct contact between infected and susceptible individuals, and carnivores often interact closely at carcasses (Mills 1993; Roelke-Parker et al. 1996; Butler et al. 2004; Ogada et al. 2012). Also, numbers of free-ranging dogs have reached unprecedented numbers in many areas of Africa. Dogs outcompete vultures on wildlife reserve boundaries owing to their high densities, nocturnal and diurnal activity, physical dominance and greater tolerance to human disturbance (Butler and du Toit 2002). The cascade effects, and its potential effects for disease spread as vultures decline, are complex. For example, changes in abundance of other avian scavengers (tawny eagles Aquila rapax) were most pronounced in the absence of vultures (Ogada et al. 2012).

Finally, in natural systems scavengers are part of a food chain that may be initiated by the action of predation. Changes in predation rates or predator-prey 
dynamics are among the factors that may affect patterns of disease emergence, reemergence, and persistence (Choo et al. 2003; Packer et al. 2003; Holt and Roy 2007). Ecosystems altered by removal of natural predators by humans may respond differently to endemic or novel pathogens than intact systems (Heesterbeek and Roberts 1995; Gross and Miller 2001; Packer et al. 2003). A mathematical model evaluated how dynamics of prion disease in deer populations may respond to nonrandom removal resulting from selective predation by wolves compared with effects of random removal through harvest or culling under different scenarios. The conclusion was that as CWD distribution and wolf range overlap in the future, wolf predation may suppress disease emergence or limit prevalence (Wild et al. 2011).

\section{Management of Scavenging to Reduce Disease Risks}

Preventing the entrance and/or controlling levels of disease in a system are the first strategy. Attempts to control disease in wildlife populations have been based on a variety of methods. These include setting up barriers, improving hygienic measures, culling, habitat management and feeding bans, vector control, treatments, and vaccination (Wobeser 2002; Artois et al. 2009; Karesh et al. 2005; Gortazar et al. 2006). Leaving entrails or carcasses in situ is an option when game animals are hunted in their natural habitat. Also, when livestock are not suspected of being infected with diseases transmissible to humans or other animals or affected with any potential hazard and good hunting practices are observed. This is recommended to protect natural ecological processes. In the case of big game remains should follow a veterinarian inspection (at least of the offal), if there is evidence that relevant pathogens circulate in the region. In this case, it becomes essential disease surveillance and monitoring of big game diseases (see above), and in general of wildlife in the area.

Once disease is present, re-directing scavenging activity and restoring predator and scavenger communities might provide useful strategies to reduce disease risks, realizing that eradication of disease may be impossible in the presence of wildlife disease reservoirs. For example, the observation of scavenging in TB multi-host systems from New Zealand may provide a mechanism for the potential control strategy of the disease in different contexts (Barron et al. 2015). Ferrets and pigs were predicted to act as a host complex via reciprocal scavenging, and it was suggested that moderately intensive control of either species was able to reduce their combined abundance below the threshold for disease persistence. Nonetheless, in most cases the selection and implementation of appropriate management is complex. Following, we provide examples and list different management approaches of scavenging that could help to reduce disease risks, although without exception, these types of approaches warrant further evaluation. In addition to surveillance of scavenging activity (e.g. using camera traps), monitoring disease in the community and how it responds to changes in scavenging activity and management becomes important, but to date has been rarely addressed. 


\section{Restoration of Large Predators}

Wolves, for example, may be able to recover functional predator-prey-scavenger food webs (Beschta and Ripple 2009). The restoration of natural predator-prey dynamics in ecosystems previously altered by removal of natural predators may contribute to counteract disease emergence (Heesterbeek and Roberts 1995; Gross and Miller 2001; Choo et al. 2003; Packer et al. 2003; Holt and Roy 2007; Wild et al. 2011). This provides an opportunity to observe and evaluate the effects that predation (selective or not) may have on the prevalence of diseases. For instance, wolves may be a promising approach for control of CWD and therefore risks associated to scavenging (Wild et al. 2011).

\section{Elimination of Hunting of Scavengers}

This has been suggested to maintain coyote populations on or adjacent to elk feed grounds in the Greater Yellowstone Area (GYA), because it may increase scavenging rates and subsequently decreases investigation rates (contact with infected material) by elk and thus risk for Brucella infection from abortions associated with elk feeding grounds (Cook et al. 2004; Maichak et al. 2009). Elk fetuses (elk abortions may transmit brucellosis) were placed in the GYA to determine which predators visited and how long the carrion lasted on the landscape. Inside Yellowstone, where scavengers such as coyotes are not hunted, the fetuses disappeared more quickly (most before 20 days, Cook et al. 2004). Scavengers have not been implicated in transmission of brucellosis from wildlife to livestock. Thus, the authors suspect that scavengers reduce brucellosis transmission by limiting the time an infectious fetus remains in the environment.

\section{Destruction of Big Game and Domestic Animal Carcasses}

We previously exemplified that, in most cases, no research has concluded what the relevance of different species of scavengers, carrion and the environment are to maintain and transmit pathogens. Nonetheless, drastic measures are often preventively taken to prevent an alleged disease spread. For instance, the destruction of big game and domestic animal carcasses has been encouraged by some European policies, rather than allowing carcasses or offal from being left in the open (Donázar et al. 2009a, b). This still arises controversy concerning vulture conservation (see above). As suggested for CWD in high-risk regions from North America (Jennelle et al. 2009), recent laws on TB endemic areas in south and central Spain have considered the removal of hunted animals (including offal) to limit potential TB deposition near a kill site that mammals, and particularly wild boar, can access. It is 
therefore desirable that management and legislation be applied in a way that would allow for the selective access of vultures to the abandoned carcasses and offal piles that appear during hunting seasons. Although sanitary authorities should consider the removal of infected hunted animals and viscera to limit potential pathogen contamination where facultative scavengers can access, the conservation of obligate scavengers and other birds requires of selective disposal that guarantees their food supply. Burial or burning carcasses (the last is considered often the optimal carcass decontamination measure) is not always logistically feasible. Other options include spraying carcasses with considerable quantities of 5 to $10 \%$ formalin or covering them with locally available obstructive materials (e.g., bushes, branches) to deter some scavengers, such as birds, but probably not mammals. In parts of Africa with fuel shortages and poor infrastructures, anthrax contaminated carcasses have been covered in thorn scrub and left. In Canada, the helicopter dump 400 gallons of 5\% formaldehyde over carcasses very effectively discouraged all scavenging until the burning team could reach the site; which presumably limited the ground contamination (Hugh-Jones and de Vos 2002). Neither of these methods will deter hyenas, which were seen to overturn a drum with $10 \%$ formaldehyde and eat formalinsaturated animal organs. In most cases, it is unlikely that all carcasses can be located (e. g. natural deaths, injured animals during hunting activities), even following intensive searches, therefore measures can only be taken on what can be found. The effectiveness of removing carcasses is not always clear, as when employed during botulism outbreaks in wild birds do not appear to have reduced avian mortality (Wobeser 2007). Nonetheless, in this particular example pathogen transmission is not mediated by carcass consumption, and probably the rapid effect of scavengers would limit environmental contamination. One final remark, which is discussed elsewhere in this chapter, is that the root cause often is related to big game overabundance contexts (Gortazar et al. 2006) favoring both high prevalence of pathogens in the population (as a density dependent mechanism) and elevated production of carrion.

\section{Restoration of the Effects of Overabundance}

We above highlighted the relationship between overabundance and disease, and therefore control of the situation will lead to limiting the associated risks. The assessment of overabundance and the available management tools have been discussed recently (Gortazar et al. 2006). A multidisciplinary approach is needed to diagnose if a given wildlife population is overabundant, which includes signs such as adverse effects on the soil, vegetation or fauna, poor body condition scores, low reproductive performance or increased parasite burdens and infectious disease prevalence. A close monitoring of wildlife densities and diseases, the establishment of reference values for all signs of overabundance, and the mapping of the disease and density hotspots will be needed to design adequate management for each particular situation. 


\section{Excluding Mammalian and Avian Scavengers from Natural Carrions}

We found just one study that experimentally evaluated the effect of excluding mammalian and avian scavengers from natural carrion on the risk for disease persistence and transmission, particularly anthrax (Bellan et al. 2013). When the only alternative is to leave the carcass unmoved and to protect it adequately from scavengers and humans, stopping scavengers can significantly reduce spore production, but this can be difficult. Nonetheless, B ellan et al. (2013) found no significant effect of scavengers on soil spore density in Etosha National Park (ENP), Namibia. They concluded that scavenging by vertebrates is not a critical factor in the life cycle of Bacillus anthracis and that anthrax control measures relying on deterrence or exclusion of vertebrate scavengers to prevent sporulation are unlikely to be effective. Consumption of carcass material early after host death may reduce the quantity of vegetative cells available to sporulate.

\section{Excluding Mammalian and Avian Scavengers from Vulture Restaurants}

Vulture restaurants, where access to facultative mammalian scavengers is impeded, can be used as a conservation tool for threatened vultures, as these places can be supplied with a source of supplementary carrion free from risky pathogens, toxicants and veterinary drugs. Nonetheless, not all are advantages, and there may be several negative impacts of supplementary feeding sites on ecosystem and scavenging community dynamics from an ecological and conservation perspective (Donázar et al. 2009a, b; Moreno-Opo et al. 2015). The provision of carrion at specific locations close to breeding sites, in accordance with requirements of sanitary regulations for the management of animal by-products not intended for human consumption has partly mitigated the negative effects of widespread and compulsory removal of livestock carcasses from the wild. Because of the apparent contradictions between the application of sanitary and conservation strategies, managers and policy makers must solve a problem of availability of food for one of the most threatened wildlife groups (vultures), at the same time that make it compatible with food security policies. Wild ungulate waste may mitigate these effects. For instance, a sufficient amount of carrion from big game is already generated in large areas (in Mediterranean areas from Spain may reach about $40 \%$ of obligate scavenger diet, and nearly $100 \%$ during hunting season, Margalida et al. 2012; see also Mateo-Tomás and Olea 2010 in northern areas of the Iberian peninsula), and the question is how ensuring the supply of big game waste management with not sanitary risks for other groups of animals and humans. Nonetheless, when not protected against mammals, there is evidence that vulture restaurants 
increase the local abundance of mammalian carnivores in South Africa (i.e. brown hyaena Hyaena brunnea and black-backed jackal; Yarnell et al. 2015), which require that the wider impacts of providing supplementary carrion for conserving threatened species are fully investigated. In fact, vultures may serve as sanitary filters because they clean up the environment by eating carrion. One possible solution is the use of mammal-proof enclosures or other effective barriers (high game fences), having a minimum area for allowing large birds landing and taking off. It has been demonstrated that some models of electrified fences were effective for preventing facultative mammal scavengers from gaining access into an enclosure for a period of time sufficient for avian scavengers to access and remove potentially infectious hunting remains (Moreno-Opo et al. 2012). Nonetheless, it is difficult to ensure that rodents and other mammals that e asily burrow or climb cannot gain access to infected carcasses. We note that restricting carrion access to birds also may affect the species that benefit from carrion (e.g. endangered species such as the brown bear and wolf in Spain); which often exert a natural effect of controlling diseases. In addition there may occur other collateral effects, such as an increase of attacks by predators on cattle or hunting when carrion is not available anymore. A condition previous to the exclusion of mammalian and avian scavengers from natural carrions in vulture restaurants should be a rigorous assessment of how they depend on carrion and what their ecosystem role is (e. g. for large predators, usually very threatened). Understanding the functionality of the assemblage of scavenging species is essential, as they "work together", benefitting from each other; for instance, wolves opening the carcass may make innards more available to crows.

A recent observational study in south-central Spain (Cano-Terriza et al. 2018) evaluated the management of big game remains aimed at reducing the access of facultative scavengers, using wild boar-proof vulture restaurants or eliminating the carrion (burial or removal by waste management firms authorized by the administration). In the study region, among other factors, intensive management of wild ungulates for hunting has led to an increase in their populations, implying a higher generation of hunting waste, which in turn can favor the transmission of infectious diseases, including TB. The above-mentioned study assessed the usefulness of disposal/elimination of hunting remains as a TB control measure in wild boar, comparing two adjacent regions where the management of these remains according to legislation varied. The Mycobacterium tuberculosis complex (MTC) seroprevalence detected in wild boar was significantly higher before the disposal of big game hunting by-products compared to the second period where control measures were applied (after this control measure a $25 \%$ reduction was achieved). By contrast, no significant differences in seroprevalence against MTC between periods were found in wild boar from the adjacent control area where carrion management was not implemented. This study suggests that the management of hunting waste in specific sites may yield some outcome of limit TB prevalence in wild boar. However, further studies are needed to assess the effect of scavenging management on the health status of wildlife species. 


\section{Conclusions and Future Perspectives}

There is an increasing concern on the exposure of scavenger communities to disease, their effects on scavengers, and the epidemiological role that scavenging plays in disease dynamics. This chapter evidences that, with some rare exceptions, research up to date does not reliably conclude what the role of different species of scavengers in the maintenance and transmission of diseases and/or the role of carrion are. Disease transmission associated to scavenging is extremely difficult to study in the field because these phenomena are not straightforward to observe and parameterize. Inferences about the pathogen maintenance by scavengers, carrion and the environment have been made mainly using sources of evidence that may be considered circumstantial. To now, it is only by the accumulation of additional pieces of correlational evidence that the acceptation of such inferences has been generally adopted. There are some examples where scavengers, including specialist and facultative, have been regarded as potential vectors for a number of diseases, in which they ingest or are exposed to infected material and later shed the disease agent in new areas. Scavenging of infectious remains poses a confounding duality between the removal of infectious materials by consumption and potential dispersion of infectious material in the environment. We illustrate in this chapter that we can benefit enormously in learning from previous experiences. Current evidences support the need for further research regarding scavenger ecology within the context of wildlife and human health, and also for wildlife management and conservation. First, research must determine the possible cascade of pathogens through food webs. Research should also assess which disposal regime is most beneficial to obligate scavengers, thus guaranteeing their food supply, while reducing the exposure of susceptible animals to potentially infectious material. Experimental research should determine susceptibility of scavenger species to infections and the likelihood pathogen passage through the gastrointestinal tract. Management of diseases and subsequent reduction in the generation of hazardous carcasses and remains usually require changes in human activities and close collaborations among wildlife ecologists, veterinarians and public health professionals. We should work towards a more informed management of scavenging. In accordance, the regulations concerning carrion provisioning need to be flexible, reconciling sanitary and environmental objectives.

Acknowledgements We thank Pedro P. Olea and Patricia Mateo-Tomás their valuable guidance and comments on the chapter.

\section{References}

Acevedo P, Vicente J, Höfle U, Cassinello J, Ruiz-Fons F, Gortazar C (2007) Estimation of European wild boar relative abundance and aggregation: a novel method in epidemiological risk assessment. Epidemiol Infect 135:519-527

Alexander KA, Kat PW, Wayne RK, Fuller TK (1994) Serologic survey of selected canine pathogens among free-ranging jackals in Kenya. J Wildl Dis 30:486-491 
Anderson DP, Ramsey DSL, de Lisle GW, Bosson M, Cross ML, Nugent G (2015) Development of integrated surveillance systems for the management of tuberculosis in New Zealand wildlife. N Z Vet J 63:89-97

Apollonio M, Andersen R, Putman R (2010) Introduction. In: Apollonio M, Andersen R, Putman $\mathrm{R}$ (eds) European ungulates and their management in the 21st century. Cambridge University Press, Cambridge

Artois M, Bengis R, Delahay RJ, Duchêne M, Duff JP, Ferroglio E et al (2009) Wildlife disease surveillance and monitoring. In: Delahay RJ, Smith GC, Hutchings MR (eds) Management of disease in wild mammals. Springer, Tokyo, pp 187-213

Barron MC, Tompkins DM, Ramsey DSL, Bosson MAJ (2015) The role of multiple wildlife hosts in the persistence and spread of bovine tuberculosis in New Zealand. N Z Vet J 63:68-76

Bellan SE, Turnbull PCB, Beyer W, Getz WM (2013) Effects of experimental exclusion of scavengers from carcasses of anthrax-infected herbivores on Bacillus anthracis sporulation, survival, and distribution. Appl Environ Microbiol 79:3756-3761

Beschta RL, Ripple WJ (2009) Large predators and trophic cascades in terrestrial ecosystems of the western United States. Biol Conserv 142:2401-2414

Briones V, de Juan L, Sánchez C et al (2000) Bovine tuberculosis and the endangered Iberian lynx. Emerg Infect Dis 6(2):189-191

Bruning-Fann CS, Schmitt SM, Fitzgerald SD et al (2001) Bovine tuberculosis in free-ranging carnivores from Michigan. J Wildl Dis 37:58-64

Butler JRA, du Toit JT (2002) Diet of free-ranging domestic dogs (Canis familiaris) in rural Zimbabwe: implications for wild scavengers on the periphery of wildlife reserves. Anim Conserv 5:29-37

Butler JRA, du Toit JT, Bingham J (2004) Free-ranging domestic dogs (Canis familiaris) as predators and prey in rural Zimbabwe: threats of competition and disease to large wild carnivores. Biol Conserv 115:369-378

Byrom A (2004) Spread of Tb by ferrets in the northern South Island high country. Landcare Research Contract Report: LC0304/146

Byrom AE, Caley P, Paterson BM, Nugent G (2015) Feral ferrets (Mustela furo) as hosts and sentinels of tuberculosis in New Zealand. N Z Vet J 63:42-53

Cano-Terriza D, Risalde MA, Jiménez-Ruiz S et al (2018) Management of hunting waste as control measure for tuberculosis in wild ungulates in south-central Spain. Transbound Emerg Dis 65(5):1190-1196

Carrasco-Garcia R, Barroso P, Perez-Olivares J, Montoro V, Vicente J (2018) Consumption of big game remains by scavengers: a potential risk as regards disease transmission in central Spain. Front Vet Sci 5:4

Clark NJ, Clegg SM (2017) Integrating phylogenetic and ecological distances reveals new insights into parasite host specificity. Mol Ecol 26:3074-3086

Choo K, Williams PD, Day T (2003) Host mortality, predation, and the evolution of parasite virulence. Ecol Lett 6:310-315

Cook WE, Williams ES, Dubay SA (2004) Disappearance of bovine fetuses in northwestern Wyoming. Wildl Soc Bull 32:254-259

Daszak P, Cunningham AA, Hyatt AD (2000) Emerging infectious diseases of wildlife-Threats to biodiversity and human health. Science 287:443-449

Delahay RJ, Smith GC, Barlow AM, Walker N, Harris A, Clifton-Hadley RS, Cheeseman CL (2006) Bovine tuberculosis infection in wild mammals in the south-west region of England: a survey of prevalence and a semi-quantitative assessment of the relative risks to cattle. Vet $\mathrm{J}$ 164:90-105

DeVault TL, Rhodes OE, Shivik JA (2003) Scavenging by vertebrates: behavioural, ecological, and evolutionary perspectives on an important energy transfer pathway in terrestrial ecosystems. Oikos 102:225-234

Donázar JA, Cortés-Avizanda A, Carreta M (2009a) The role of trophic resource predictability in the structure of scavenger guild. Vultures, feeding stations and sanitary legislation, a conflict and its consequences from the perspective of conservation biology. Munibe 29:344-352 
Donázar JA, Margalida A, Carrete M, Sánchez-Zapata JA (2009b) Too sanitary for vultures. Science 326:664

EFSA (European Food Safety Authority) (2017) Scientific report on the European Union summary report on surveillance for the presence of transmissible spongiform encephalopathies (TSE) in 2016. EFSA J 15(5069):68

European Commission - Health \& Consumer Protection Directorate-General (2002) Scientific Steering Committee. Opinion on: necrophagous birds as possible transmitters of TSE/ BSE. Adopted by the scientific steering committee at its meeting of 7-8 November 2002. https://ec.europa.eu/food/sites/food/files/safety/docs/sci-com_ssc_out295_en.pdf

Farner DS (1967) The hydrogen ion concentration in avian digestive tracts. Poultry Sci 21:445

Ferroglio E, Gortazar C, Vicente J (2011) Wild ungulate diseases and the risk for livestock and public health. In: Putman R, Apollonio M, Andersen R (eds) Ungulate management in Europe: problems and practices. Cambridge University Press, Cambridge

Glass CM, Mclean RG, Katz JB et al (1994) Isolation of pseudorabies (Aujeszky's disease) virus from a Florida panther. J Wildl Dis 30:180-184

Gortazar C, Acevedo P, Ruiz-Fons F, Vicente J (2006) Disease risks and overabundance of game species. Eur J Wildl Res 52:81-87

Gortazar C, Torres MJ, Vicente J et al (2008) Bovine tuberculosis in Doñana Biosphere Reserve: the role of wild ungulates as disease reservoirs in the last Iberian lynx strongholds. PLoS One $3: 1-8$

Gortazar C, Vicente J, Fierro Y, Leon L, Cubero MJ, González M (2002) Natural Aujeszky's disease in a Spanish wild boar population. Ann N Y Acad Sci 969:210-212

Gross JE, Miller MW (2001) Chronic wasting disease in mule deer: disease dynamics and control. J Wildl Manag 65:205-215

Harrison TM, Mazet JK, Holekamp KE, Dubovi E, Engh AL, Nelson K, Van Horn RC, Munson L (2004) Antibodies to canine and feline viruses in spotted hyena (Crocuta crocuta) in the Masai Mara National Reserve. J Wildl Dis 40:1-10

Heesterbeek JAP, Roberts MG (1995) Mathematical models for microparasites of wildlife. In: Grenfell BT, Dobson AP (eds) Ecology of infectious diseases in natural populations. Cambridge University Press, Cambridge, pp 90-122

Holt RD, Roy M (2007) Predation can increase the prevalence of infectious disease. Am Nat 169:690-699

Houston DC, Cooper JE (1975) The digestive tract of the whitebacked griffon vulture and its role in disease transmission among wild ungulates. J Wild Dis 11:306-313

Hugh-Jones ME, De Vos V (2002) Anthrax and wildlife. Rev Sci Tech 21:359-383

Hutson JM, Burke C, Haynes G (2013) Osteophagia and bone modifications by Giraffe and other large ungulates. J Archaeol Sci 40:4139-4149

Inger R, Cox DTC, Per E, Norton BA, Gaston KJ (2016) Ecological role of vertebrate scavengers in urban ecosystems in the UK. Ecol Evol 6:7015-7023. https://doi.org/10.1002/ece3.2414

Jennelle CS, Samuel MD, Nolden CA, Berkley EA (2009) Deer carcass decomposition and potential scavenger exposure to chronic wasting disease. J Wildl Manag 73:655-662

Karesh WB, Cook RA, Bennett EL, Newcomb J (2005) Wildlife trade and global disease emergence. Emerg Infect Dis 11:1000-1002

Leighton FA, Artois M, Capucci L, Gavierwiden D, Morisse JP (1995) Antibody-response to rabbit viral hemorrhagic disease virus in red foxes (Vulpes vulpes) consuming livers of infected rabbits (Oryctolagus cuniculus). J Wildl Dis 31:541-544

Maichak EJ, Scurlock BM, Rogerson JD, Meadows LL, Barbknecht AE, Edwards WH, Cross PC (2009) Effects of management, behavior, and scavenging on risk of brucellosis transmission in elk of western Wyoming. J Wildl Dis 45:398-410

Margalida A, Colomer MA (2012) Modelling the effects of sanitary policies on European vulture conservation. Sci Rep 2:753

Margalida A, Carrete M, Sánchez-Zapata JA, Donázar JA (2012) Good news for European vultures. Science 335:284-284 
Margalida A, Moleón M (2016) Toward a carrion-free ecosystem. Front Ecol Environ 14:182-183

Markandya A, Taylor T, Longo A, Murty MN, Murty S, Dhavala K (2008) Counting the cost of vulture decline: an appraisal of the human health and other benefits of vultures in India. Ecol Econ 67:194-204

Martín-Hernando MP, Höfle U, Vicente J et al (2007) Lesions associated with Mycobacterium tuberculosis complex infection in the European wild boar. Tuberculosis 87:360-367

Masot AJ, Gil M, Risco D, Jiménez OM, Núñez JI, Redondo E (2016) Pseudorabies virus infection (Aujeszky's disease) in an Iberian lynx (Lynx pardinus) in Spain: a case report. BMC Vet Res 13:6

Mateo-Tomás P, Olea PP (2010) When hunting benefits raptors: a case study of game species and vultures. Eur J Wildl Res 56:519-528

Mateo-Tomás P, Olea PP, Moleón M, Vicente J, Botella F, Selva N, Viñuela J, Sánchez-Zapata JA (2015) From regional to global patterns in vertebrate scavenger communities subsidized by big game hunting. Divers Distrib 21:913-924

Mateo-Tomás P, Olea PP, Moleón M, Selva N, Sánchez-Zapata JA (2017) Both rare and common species support ecosystem services in scavenger communities. Glob Ecol Biogeogr 26:1459-1470

Millan J, Jimenez MA, Viota M, Candel MG, Peña L, León-Vizcaino L (2008) Disseminated bovine tuberculosis in a wild red fox (Vulpes vulpes) in southern Spain. J Wildl Dis 44:701-706

Miller MW, Williams ES, Hobbs NT, Wolfe LL (2004) Environmental sources of prion transmission in mule deer. Emerg Infect Dis 10:1003-1006

Mills MGL (1993) Social systems and behaviour of the African wild dog Lycaon pictus and the spotted hyaena Crocuta crocuta with special reference to rabies. Onderstepoort J Vet Res 60:405-409

Moreno-Opo R, Trujillano A, Margalida A (2015) Optimization of supplementary feeding programs for European vultures depends on environmental and management factors. Ecosphere 6(7):127

Moreno-Opo R, Margalida A, García F, Arredondo A, Rodríguez C, González LM (2012) Linking sanitary and ecological requirements in the management of avian scavengers: effectiveness of fencing against mammals in supplementary feeding sites. Biodivers Conserv 21:673-1685

Naranjo V, Gortazar C, Vicente J, de la Fuente J (2008) Evidence of the role of European wild boar as a reservoir of Mycobacterium tuberculosis complex. Vet Res 127:1-9

Newsome TM, Dellinger JA, Pavey CR et al (2014) The ecological effects of providing resource subsidies to predators. Glob Ecol Biogeogr 24:1-11

Nichols TA, Fischer JW, Spraker TR, Kong Q, VerCauteren KC (2015) CWD prions remain infectious after passage through the digestive system of coyotes (Canis latrans). Prion 9:367-375

Oaks JL, Gilbert M, Virani MZ et al (2004) Diclofenac residues as the cause of vulture population decline in Pakistan. Nature 427:630-633

Ogada DL, Torchin ME, Kinnaird MF, Ezenwa VO (2012) Effects of vulture declines on facultative scavengers and potential implications for mammalian disease transmission. Conserv Biol 26:453-460

Packer C, Holt RD, Hudson PJ, Lafferty KD, Dobson AP (2003) Keeping the herds healthy and alert: implications of predator control for infectious disease. Ecol Lett 6:797-802

Pain DJ et al (2003) Causes and effects of temporospatial declines of Gyps vultures in Asia. Conserv Biol 17:661-671

Pedersen AB, Jones KE, Nunn CL, Altizer S (2007) Infectious diseases and extinction risk in wild mammals. Conserv Biol 21:1269-1279

Pérez J, Calzada J, León-Vizcaino L, Cubero MJ, Velarde J, Mozos E (2001) Tuberculosis in an Iberian lynx (Lynx pardina). Vet Rec 148:414-415

Probst C, Globig A, Knoll B, Conraths FK, Depner K (2016) Behaviour of free ranging wild boar towards their dead fellows: potential implications for the transmission of African swine fever. R Soc Open Sci 4(5):170054 
Roelke-Parker ME et al (1996) A canine distemper outbreak in Serengeti lions (Panthera leo). Nature 379:441-445

Roen KT, Yahner RH (2005) Behavioral responses of avian scavengers in different habitats. Northeast Nat 12:103-112

Seidel B, Thomzig A, Buschmann A, Groschup MH, Peters R, Beekes M, Terytze K (2007) Scrapie agent (strain 263k) can transmit disease via the oral route after persistence in soil over years. PLoS One 2:E435.10.1371

Selva N, Jedrzejewska B, Jedrzejewski W, Wajrak A (2005) Factors affecting carcass use by a guild of scavengers in European temperate woodland. Can J Zool 83:1590-1601

Sharp D (2006) Meloxicam to prevent rabies? Lancet 367:887-888

Smith CR (1994) Wild carnivores as plague indicators in California: a cooperative interagency disease surveillance program. In: Halverson WS, Crabb AC (eds) Proceedings of 16th vertebrates pest conference. University of California, Davies, pp 192-199

Towne EG (2000) Prairie vegetation and soil nutrient responses to ungulate carcasses. Oecologia 122:232-239

Turner KL, Abernethy EF, Conner LM, Rhodes OE Jr, Beasley JC (2017) Abiotic and biotic factors modulate carrion fate and vertebrate scavenging communities. Ecology 98:2413-2424

VerCauteren KC, Atwood TC, DeLiberto TJ, Smith HJ, Stevenson JS, Thomsen BV, Gidlewski T, Payeur J (2008) Sentinel-based surveillance of coyotes to detect bovine tuberculosis, Michigan. Emerg Infect Dis 14:1862-1869

VerCauteren KC, Pilon JL, Nash PB, Phillips GE, Fischer JW (2012) Prion remains infectious after passage through digestive system of American crows (Corvus brachyrhynchos). PLoS One 7(10):e45774

Vicente J, Carrasco R, Acevedo P, Montoro V, Gortazar C (2011) Big game waste production: sanitary and ecological implications. In: Kumar S (ed) Integrated waste management, vol 2. Intech, Rijeka

Wild MA, Hobbs NT, Graham MS, Miller MW (2011) The role of predation in disease control: a comparison of selective and nonselective removal on prion disease dynamics in deer. J Wild Dis 47:78-93

Wilmers CC, Crabtree RL, Smith DW, Murphy KM, Getz WM (2003a) Trophic facilitation by introduced top predators: grey wolf subsidies to scavengers in Yellowstone National Park. J Anim Ecol 72:909-916

Wilmers CC, Stahler DR, Crabtree RL, Smith DW, Getz WM (2003b) Resource dispersion and consumer dominance: scavenging at wolf- and hunter-killed carcasses in Greater Yellowstone, USA. Ecol Lett 6:996-1003

Wilson EE, Wolkovich EM (2011) Scavenging: how carnivores and scavenging structure communities. Trends Ecol Evol 26:129-135

Wobeser GA (2007) Disease in wild animals: investigation and management. Springer, Berlin

Wobeser GA (2002) Disease management strategies for wildlife. Rev Sci Tech 21:159-178

Yarnell RY, Phipps WL, Dell S, MacTavish LM, Scott DM (2015) Evidence that vulture restaurants increase the local abundance of mammalian carnivores in South Africa. Afr J Ecol 53:287-294

Zanin E, Capua I, Casaccia C, Zuin A, Moresco A (1997) Isolation and characterization of Aujeszky's disease virus in captive brown bears from Italy. J Wildl Dis 33:632-634 